\title{
Meghnad Saha: work, life and times
}

\author{
Rajesh Kochhar \\ Mathematics Department, Panjab University, Chandigarh 160014 India \\ email: rkochhar2000@gmail.com
}

\begin{abstract}
It is no coincidence that IAU and Saha's ionization formula are about the same age. Both events are related to World War 1 and connected with Germany though in entirely different ways.

Once sufficiently large number of stellar spectra had been obtained and empirically classified according to the Harvard scheme, it was inevitable that theoretical explanation would be forthcoming. The only surprise was that the breakthrough came from the far-off Calcutta which was nowhere on the world research map.

History chose the hour; the hour produced an unlikely hero: Meghnad Saha. Calcutta University had just become a research centre under Indian auspices. By a fortuitous combination of circumstances immediately after the war, the latest German language physics publications arrived in Calcutta as a personal library. While Europe needed time to resume scientific exchanges and activity, India seized the opportunity and produced two outstanding pieces of theoretical work: Saha's ionization formula (1920), and Bose statistics (1926). It is to the credit of The Royal Society that it elected Saha as a member (1927) in spite of the government's objections arising from Saha's anti-British stance. Saha however was unable to carry out further observational and experimental work suggested by the theory.

Saha was a multi-faceted personality with strong views on political ideology, the role of science in a new nation and other topics. India's charismatic Prime Minister, Jawaharlal Nehru, during 1947-1964 had a soft corner for sophisticated, suave, upper-crust people. Impatient and angry, confrontational rather than persuasive, Saha did not qualify.

Saha is justly regarded as one of the founders of theoretical astrophysics. Examination of his life and work is a rewarding exercise from various points of view: development of modern astronomy; Western science and the non-West; and political and social activism of a leading scientist and educator.
\end{abstract}

Keywords. Astronomy in India, Meghnad Saha, Saha ionization formula, Bose-Einstein statistics

\section{Introduction}

It is no coincidence that IAU and the Saha ionization formula are about the same age. Both events are related to World War 1, and connected with Germany, though in entirely different ways.

By the 1910s, a vast amount of data on solar and stellar spectra had been obtained and an obviously meaningful empirical spectral classification scheme devised. It was inevitable that sooner or later the theoretical basis for it would be found. History chooses the hour; and the hour produces the hero. The only surprise was that the hour was seized not in any established research centre in the West but in a far-off Calcutta which was nowhere on the world research map.

Meghnad Saha (1893-1955) set out his theory in a number of papers published in British journals during 1920-1921. The work was immediately recognized as laying the foundation of quantitative astrophysics. Saha showed that astronomical spectra of 
all kinds, notwithstanding their seeming complexity and diversity, can be rigorously explained in terms of known laws and chemical elements, by simply invoking different physical conditions. Saha's work thus transformed the cosmos from an exotic out-field into a science lab.

\section{Saha's early work in Calcutta and the ionization formula}

Saha's first two papers, including the one that gave the ionization formula, were published before he left for Europe for the first time. Much to his annoyance, an impression persisted in the West that Saha did his pioneer work while in England, implying that 'an Indian was incapable of making breakthrough discoveries without western training or western assistance' (DeVorkin 1994, p. 156).

The educated Indians viewed cultivation of modern science as an extension of their nationalist movement. By the beginning of the 19th century, the English-knowing Bengal middle class had become articulate and assertive, and come to occupy responsible positions in the colonial establishment. The first successful attempt to transform Calcutta University from a merely affiliating and examining body into a science research and education centre was made by Sir Asutosh Mookerjee (1864-1924), who was a High Court judge and served as the part-time vice-chancellor from 1906-1914, and then again for another two-year term 1921-1923. Asutosh held dual MA degrees in mathematics (1885) and physical science (1886), and would have liked to become a lecturer in mathematics at the Calcutta University, but the first Indian vice-chancellor, Sir Gooroodas Bannerjee (1844-1918), who held office during 1890-1892, was unable to raise the requisite funds. A disappointed Asutosh then shifted to law. In 1912, he initiated a vigorous drive for the establishment of University College of Science, beginning with munificent donations from two lawyers - it would have been a rather easy task for a judge to persuade lawyers. The foundation stone of the College was laid in 1914 which became functional in 1916.

Saha passed his MSc in 'mixed mathematics' in 1915 from the Presidency College Calcutta. [S.N.] Bose (of Bose-Einstein statistics, 1924) was his class fellow. Both were appointed lecturers in mathematics in 1916, but transferred to the physics department the next year. Two professorships were created. The experimental physicist C.V. Raman would join as Palit professor and head of the department in July 1917. The other professorship, named after Ghose, was offered to the England-educated, well-connected, Debendra Mohan Bose (1885-1975), in 1914, who in addition was awarded a two-year European travelling fellowship. He chose to go to Berlin, where he had to remain till the war ended. His internment in Germany would prove to be very beneficial for Indian physics. In the absence of the professors, the task of designing the courses and delivering lectures dwelt on the two young lecturers, Saha and Bose, who themselves had not studied advanced physics as students. They taught themselves physics to be able to teach their students, and in the process became world-renowned researchers themselves. Though Saha and Bose were part of the British Empire, professionally they were children of Germany. Their physics education came through German-language books, in two instalments.

\section{Johannes Brühl and his assistance to Saha}

Professor Paul Johannes Brühl (1855-1935) was born in the village Weifa in Bautzen district of the Sachsen state in Germany, and he made India his home for reasons of health (TB). During 1878-1881, he travelled through central Europe, Turkey, Asia Minor and Armenia collecting plant specimens, and arrived at his destination of Bengal in July 1881. Even though his world fame rests on his contributions to botany, he was a versatile scientist. In an era when most senior positions in the colonial education service were filled 
by 'third-rate Scotsmen' (Mehra 1974, p. 120), a knowledgeable and dedicated European was a great asset to colonial and nationalist science and education.

In 1882 he was absorbed in the provincial education service, class I (as distinct from the higher-ranking Indian education service) and appointed professor in Rajshahi College (now in Bangla Desh). He married an English woman, Annie Betts Fox, in 1883. In 1887, Sir George King (1840-1909), the director of the Calcutta botanic garden, arranged for Brühl's transfer to the Bengal Engineering College, near Calcutta, with a view to utilizing his botanical expertise. In 1896 the two published the Century of new and rare Indian plants. This influential illustrated text would undergo 18 editions till 1971.

Brühl taught physics and held charge of the library, officiated as the principal in 1895, and served as part-time lecturer in geology at Presidency College during 1902-03. On his retirement from government service in 1912, he was made Companion of the Imperial Service Order.

He spent a few months during 1912-1913 at the Indian Institute of Science Bangalore learning chemical geology. In 1913 he accepted the post of the Calcutta University registrar which he held till 1918. He was extremely unhappy at the drudgery of the post. In early 1914 he complained to Sir David Prain, director of the Royal Botanic Gardens, Kew, that before he accepted the post, he had been informed that he would have opportunities of doing some research work. But that was not the case. He made up his mind in June 1914 to leave India for good and move to England to do botanical research at Kew (plants.jstor.org/stable/10.5555/al.ap.visual.kdcas289). Fortunately for India, he was thwarted by the war, and then the conditions changed for the better. In 1918, he was appointed professor of botany which post he held till 1928. To mark his services, his former and current students raised money to institute a Paul Johannes Brühl Memorial Medal, a triennial award for contributions to the study of Asiatic botany, to be awarded by the Royal Asiatic Society of Bengal of which he was a prominent member (biographical details are mostly from Banerjee 1935).

If Brühl had left for England in 1914, he would surely have taken his extensive personal library with him. He now made it available to Saha (who already knew some German) and Bose. Among the books they borrowed and read were the works by Maxwell and Boltzmann as also the more recent ones such as Planck's Vorlesungen über die Theorie der Wärmestrahlung (1906) and von Laue's Relativitätsprinzip (1911) (Mehra 1974, p. 504). According to Bose, Brühl himself might not have read many books he owned. It is not clear why and how Brühl acquired books he did not really need for himself.

\section{Saha and Bose}

D.M. Bose returned to Calcutta in 1919, bringing with him a large number of books, including the latest German publications. Saha and Bose now continued their selfeducation in D.M. Bose's library. Among the books they read was the 26 April 1918 special issue of Naturwissenschaften, a Festschrift on Planck's 60th birthday, containing articles by many eminent authors (Mehra 1974, p. 506).

In 1920, Saha and Bose brought out, from Calcutta University Press, the world's firstever English translation of Einstein and Minkowski's papers on relativity, written during 1905-1916. Reviewing it, Nature wrote in 1922 that it 'will be of service to those who are unfamiliar with German, and wish to grapple with the pioneer works, some of which are rather inaccessible'.

The inaccessibility was due to the war. Restoration of full European scientific activity and knowledge exchange would take some years. During this short period, India became the inheritor of German theoretical physics scholarship and extended it further. Physics was young then. With research papers, text books, and popular accounts complementing one another, it was easy to identify outstanding research problems. Both Saha and Bose 
were mathematically well-equipped to address and solve them. Saha learnt about the spectral confusion from Agnes Mary Clerke's 1903 Problems in Astrophysics, while Bose could immediately see the inner inconsistency in the derivation of Planck's Law and set out to impart rigour to it.

\section{Raman and Saha and the need for research funding}

On return from Europe in late 1921, Saha was made Khaira professor, but the personal elevation left basic issues unaddressed. Nationalist science faced a dilemma. Not enough money was forthcoming from Indian donors. In the West, science was the means of production of wealth, a part of which was ploughed back to support science. Science, however, played hardly any role in the Indian economy. Sporadic and limited funding for science came about because the individuals collecting money enjoyed social and official prestige and were well-networked. This mode was unsustainable in the long run. The colonial government was ready to help with grants, but demanded administrative control in return, which the Indian side was not willing to concede. Saha would have liked to carry out further observational and experimental work suggested by his theory, but University funding was not forthcoming. On this count, he fell out with the head of the department, Raman, who as an experimentalist would himself be in need of funds. Saha moved to Allahabad University in 1923, where he would remain till 1938 when he returned to Calcutta University to occupy the professorial chair once held by Raman. He retired in 1953 on reaching 60 years.

In 1923, Saha turned to USA for a grant to set up a spectroscopic lab. The grant might have been forthcoming if Raman had not given a negative report to Millikan on Saha's experimental abilities (DeVorkin 1994, p. 162). One can understand the turf war between Raman and Saha when they both were competing for funding from the same source. But, Raman's thwarting Saha's efforts to obtain a research grant from Rockefeller philanthropy shows pettiness of mind. Raman and Saha, both important Indian science leaders, maintained a life-long mutually antagonistic relationship.

Saha had wanted to join the government service, but was refused permission because of his pronounced anti-British stance. For the same reason, the British government would have liked The Royal Society to exclude Saha. It goes to the credit of the Society that it ignored the pressures and the hints, and elected him a fellow, in 1927. This recognition brought him an annual research grant of $£ 300$ from the Indian government followed by the Royal Society's grant of £250 in 1929 (DeVorkin 1994, p. 164). But the aid came too late.

Saha was an invitee at the prestigious international congress of physics held in Como, Italy, in September 1927, which was attended by 11 Noble laureates. The other intended invitee from India was S.N. Bose, but the organizers were shocked to discover that a wrong Bose had landed! (Kochhar 1994).

Bose's pioneer paper published in Zeitschrift für Physik in August 1924, translated and communicated by Einstein, gave the name of the author as Bose (without initials), Dacca University, India. However, in his own two follow-up papers published in September 1924 and February 1925, Einstein carelessly calls the author D. Bose. Apparently the Como organizers picked up the invitee's name from Einstein's paper rather than Bose's own. That is how D.M. Bose came to Como in place of S.N. Bose. The indistinguishable particles obeying Bose-Einstein statistics are called bosons. Seen from Europe of the day, the various Boses in Bengal were indeed bosons.

\section{Saha's place and legacy in Indian science and society}

On its part, Indian science never became self-assessing. In 1926, when Bose was in Europe on a scholarship, he applied for a professorship at Dacca. Since he did not have 
a doctorate, his friends advised him to get a letter of recommendation from Einstein. Einstein was surprised at the request; because Bose's internationally acclaimed work should have been its own recommendation. This part of the story is well known. What is not is that in spite of Einstein's recommendation, Bose was not selected for the post which was offered to D.M. Bose, and S.N. Bose placed on the waiting list. It is only when D.M. Bose decided to stay put in Calcutta that S.N. Bose was made a professor, in 1927.

When Paul Dirac visited India in the late 1950s he was shocked to discover that Bose was not an FRS. The omission reflected poorly on the Society. On Dirac's initiative, Bose was elected FRS belatedly in 1958. At the time, there were already a number of Indian Fellows, but none of them had ventured to propose Bose's name. We have here at work what may be called the Sultan's Harem Syndrome: inmates of a harem compete with one another to catch the eye of the Sultan, and prevent others from doing so, the Sultan in this case being the West.

Saha's father was a very poor shopkeeper in rural East Bengal, now Bangla Desh (see Naik 2013, for a recent biography). As a high school student, he won Rs 100 as first prize in an all-Bengal Bible competition organized by the Dacca Baptist Mission. I think the motivating factor was not so much Christianity as 100 rupees.

In the peculiar Bengal social hierarchy, his caste was ranked low (though higher than the erstwhile 'untouchables'). Caste humiliation scarred Saha for life. Casteism in a rural setting, which he experienced when he was young, would not have hurt as much as when it was practised in Calcutta in the government hostel. He was not permitted to eat at the main table nor allowed to participate in the annual worship of Sarasvati, the goddess of learning, who would have considered him his favourite child. Perhaps the upper caste boys, irked by his brilliance, wanted to show him his place. After two years of stay at the hostel, he along with a handful of his upper-caste friends moved out of the hostel to a private mess [board and lodge]. Even half a century later, he had neither forgotten nor forgiven. In the late 1950s, when inmates of the Eden Hindu hostel called on him to invite him to preside over the annual function, he refused bluntly, recalling for their information his college-day humiliation. At the time, he was an elected member of the Indian Parliament from Calcutta, having defeated a nominee of Nehru's ruling Congress Party.

Saha was quite close to Jawaharlal Nehru in the years preceding Indian independence, but the distance increased subsequently (Sur 2002). Nehru, India's charismatic Prime Minister during 1947-1964, had a soft corner for sophisticated, suave, upper-crust people. Bitter and angry, confrontational rather than persuasive, Saha, unlike Homi Jahangir Bhabha (1909-1966) and Shanti Swarup Bhatnagar (1894-1955), did not become part of big science under Nehru (Anderson 2010).

Normally, an activity begins modestly, reaches a peak, declines somewhat, and settles on a plateau. By a fortuitous combination of factors, Indian physics began at the top, but did not have the wherewithal to sustain itself; it had no place to go but down.

Given his intellectual prowess, teaching abilities, restlessness, social background, and political inclinations, Saha remained active throughout his life in various fields. But at the end of the day, as far as world science is concerned, Saha's individual brilliance remained individual.

\section{Discussion}

MALlik: Saha was close to Nehru to start with: Saha a professor of physics in Allahabad, Nehru a resident of Allahabad. Nehru, a Natural Sciences Tripos from Cambridge had a soft corner for science and considered Saha a close friend. It was with the arrival of Bhabha on the scene in 1939 that the two drifted apart as Nehru was drawn more to Bhabha, a Cambridge man. 
KochHar: That is true. If Bhabha had not come on the scene, would Nehru's rapport with Saha have continued? I do not think so. Personalities are important, but there are other factors.

DeVorkin: Saha used chemical equilibrium theory and not atomic physics to derive his ionization equation. Why is this not fully appreciated?

KochHAR: This is a good point. The point you make is noted in passing, but I wonder whether it has been analyzed.

\section{References}

Anderson, Robert S. 2010, Nucleus and Nation: Scientists, International Networks, and Power in India, (Chicago: University of Chicago Press)

Banerjee, Kalipada 1935, Current Science, 4, 231

Chatterjee, Santimay, \& Chatterjee, Enakshi 1994, Current Science 66(2): 166-170

DeVorkin, David H. 1994, Journal for the History of Astronomy, 25, 155-188

Kochhar, Rajesh 1994, The wrong Bose at Como, Economic Times, 31 May

Mehra, Jagdish 1974, Biographical Memoirs of the Royal Society (London), 21, 116-154

Mehra, Jagdish 2001, The Golden Age Of Theoretical Physics, Vol. 1 (Singapore: World Scientific)

Naik, Pramod V. 2013, Meghnad Saha, (Cham, Switzerland: Springer Nature)

Sur, Abha 2002, Historical Studies in the Physical and Biological Sciences, 33, 87-105

Wali, Kameshwar C. 2009, Satyendra Nath Bose: His Life and Times : Selected Works (with Commentary), (Singapore: World Scientific) 